\title{
The Concept, Problems and Progress of Sensor Network and Its Data Management
}

\author{
Li Wang ${ }^{1,}$, Zhaohua Wang $^{2}$ \\ ${ }^{1}$ Department of Energy Engineering, Yulin University, Yulin 719000, Shannxi, China \\ a278116312@qq.com
}

Keywords: sensor network; data management; concept; problem; progress

Abstract. With the development of society and progress of times, the economic level in China has improved significantly in recent years. In actual economic development, the level of science and technology has been greatly improved. The further development of science and technology will ultimately serve social construction. This is also an important content and main objective of science and technology. To perfect application content and application value, all original technologies are upgrading and growing actively. Sensor network is a kind of network technology eventually formed in such a development background. For this end, in this paper, the author carries out a brief study on the concept, problems and progress of sensor network and its data management.

\section{Introduction}

The $21^{\text {st }}$ Century is an era of rapid economic development and highly prosperous science and technology. In this context, the development of any objects will be affected to a large extent. For the development of science and technology, finally technical development and technical application will undergo a great impact. To further improve development content and development trend, technical development needs to be founded on basic needs of the society. Sensor network is a technical content that integrates sensing technology and evolves from multiple cutting-edge technologies. In current social development, it is of great application value. Therefore, it is of practical significance to study the concept, problems and progress of sensor network and its data management.

\section{Sensor Network}

(I) Concept of sensor network

Through further study, the concept of sensor network can be defined as follows: the so-called sensor network is actually to apply a set of sensors and then constitute this set of sensors in the form of AdHoc, so as to form a wired or wireless network. The ultimate goals of sensor network are to sense collaboratively and collect object information. It processes object information in sensing filed and then releases it to an object information observer on the other end through the network. Fig. 1 shows the basic composition of a sensor network [1].

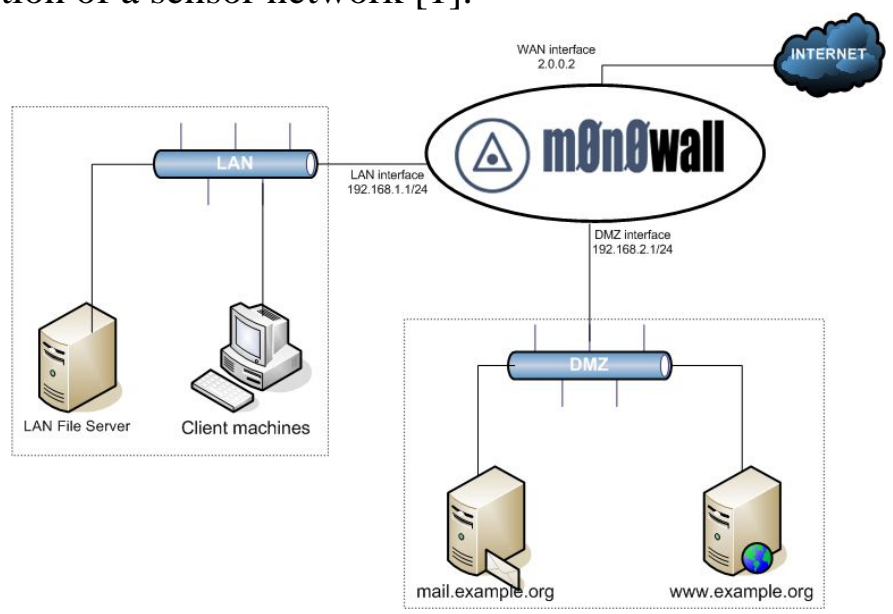

Fig. 1 A Typical Sensor Network

(II) Comparison between sensor network data management and distributed database 
Sensor network is actually made up of sensor nodes. In actual application, these sensor nodes require low costs and low energy consumption. Through wireless connection, these basic sensor nodes will finally make up a fully-distributed system without a central node as what we see now. During use, even if there is no operator operating or attending it in general work, still it shows high dynamics in actual application. But these basic advantages, in large part, directly restrict the further application of original conventional data management technology in sensor network. Fig. 2 shows the architecture of a sensor network data management system [2]. Tab. 1 shows some basic differences between WSNDMS and DDBMS.

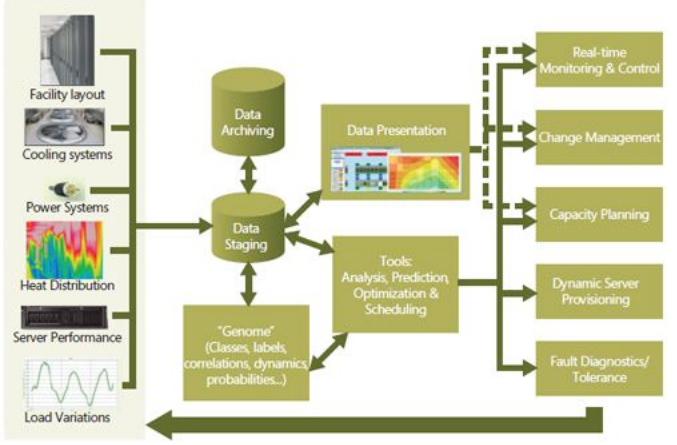

Fig. 2 Architecture of a Sensor Network Data Management System

Tab. 1 Some Basic Differences between WSNDMS and DDBMS

\begin{tabular}{lll}
\hline Item & WSNDMS & DDBMS \\
\hline Supporting environment & Wireless sensor network & Computer network \\
Object of data management & Dynamic data flow & Static data set \\
Type of queries & Continuous query & Snapshot query \\
\hline
\end{tabular}

\section{Research Problems about Sensor Network}

(1) Data storage and indexing technology of sensor nodes

Under general conditions, sensor nodes inside the sensor need to store monitoring data present in actual work or other system-related information, etc. When a sensor is designed, permanence is added and become an important part of sensor nodes. In actual design, we need to consider shock resistance and node size, etc. [3] So in the actual design process, conventional hard disk content is not suitable for the node design of sensor, because it lacks relevant design features of permanent memory. Through research, it is found that flash can play an important role in the design and final use of permanent memory. When designing sensor nodes, the design and application of data storage technology and indexing technology require us to consider basic characteristic of flash and energy consumption of nodes. Tab. 1 shows properties of some flash chips. Tab. 2 shows a comparison between data read/write power consumption of some flash chips [4].

Tab. 2 Properties of Some Flash Chips

\begin{tabular}{llll}
\hline Type & Capacity & Page Size & Erase Block \\
\hline Atmel NOR & $512 \mathrm{kB}$ & $256 \mathrm{~B}$ & 1 \\
Hitachi MMC & $32 \mathrm{mB}$ & $512 \mathrm{~B}$ & 16 \\
Micron NAND & $512 \mathrm{mB}$ & $2 \mathrm{kB}$ & 64 \\
\hline
\end{tabular}

Tab. 3 Comparison between Data Read/Write Power Consumption of Some Flash Chips

\begin{tabular}{lllll}
\hline \multirow{2}{*}{ Type } & \multicolumn{4}{l}{ Energy per Bytes } \\
\cline { 2 - 5 } & Read & Write & Erase & Total \\
Atmel NOR & 0.26 & 4.3 & 2.36 & 6.92 \\
Hitachi MMC & 0.06 & 0.575 & 0.47 & 1.108 \\
Micron NAND & 0.027 & 0.034 & N/a & 0.062 \\
\hline
\end{tabular}

In the process of existing technical development, to solve the storage problem with sensor network, corresponding storage indexing methods prosper. Although each method has a remarkable 
application in actual design, there is no perfect technology that can suit any situation. Different storage methods have very distinct shortcomings. For example, CS can be applied to any database query, but cannot be applied to large-scale network. Tab. 4 shows a comparison between characteristics of several storage indexing methods.

Tab. 4 Comparison between Characteristics of Several Storage Indexing Methods

\begin{tabular}{|c|c|c|c|c|c|}
\hline Name & $\begin{array}{l}\text { System } \\
\text { Structure }\end{array}$ & $\begin{array}{l}\text { Indexing } \\
\text { Technology }\end{array}$ & $\begin{array}{l}\text { Routing } \\
\text { Algorithm }\end{array}$ & $\begin{array}{l}\text { Applicable } \\
\text { Query }\end{array}$ & Problem \\
\hline CS & Centralized & None & $\begin{array}{l}\text { Multi-hop } \\
\text { broadcasting }\end{array}$ & $\begin{array}{l}\text { All kinds of } \\
\text { database } \\
\text { queries }\end{array}$ & $\begin{array}{l}\text { Not applicable to } \\
\text { large-scale network }\end{array}$ \\
\hline DCS & Distributed & GHT & GPSR & Point query & $\begin{array}{l}\text { When the data } \\
\text { storage position is } \\
\text { far from the data } \\
\text { generation position, } \\
\text { it will cause great } \\
\text { communication } \\
\text { overhead }\end{array}$ \\
\hline DIFS & Distributed & $\begin{array}{l}\text { GHT } \quad \& \\
\text { quadtree }\end{array}$ & $\begin{array}{l}\text { End-to-end } \\
\text { routing }\end{array}$ & $\begin{array}{l}1 \mathrm{D} \text { or } 2 \mathrm{D} \\
\text { query }\end{array}$ & Dimension limit \\
\hline
\end{tabular}

(II) Research problems about base layer

In actual development, from a certain angle, the problem with base layer is in fact software and hardware problems with sensors. The research content mainly includes the following aspects: the first aspect is to study theories and technologies about the new generation of sensors. The second aspect is to further study relevant simulation technologies. The third aspect is to study self-calibration and self-testing technologies that sensors must have. The fourth aspect is to study materials and devices of the new generation of sensors, such as the application of chemical materials, new materials and devices for sensing biological substances, etc. [5]

\section{Progress of Sensor Network}

The U.S. Army and Navy have started to apply sensor network technology very early in the process of military construction. Recently, the U.S. Navy reported technical development in mesh sensor system, which had a prominent promoting impact on the development of sensor network. In academic fields, Massachusetts Institute of Technology has begun to study ultra-low power wireless sensor network. Through research, the University of Southern California finally came up with a method to deploy a mobile sensor network in an unfamiliar environment. While Cornell University focused more on studying data processing technology and probed into a COUGAR system in actual research. After study, Harbin Institute of Technology and Heilongjiang University presented a new sensor network data model centered on data [6].

\section{Conclusion}

To sum up, the economic level in China has improved significantly in recent years. The rapid development of economy directly promotes the development of science and technology. The impetus of technical development, especially after the advent of the new century, the specific application value and social value of science and technology becomes even more striking. For technology, development is a problem and application is also a very serious problem. We need to further clarify their relationship. In this paper, the author studies the basic concept, problems and progress of sensor network and data management from their fundamentals, in the hope of facilitating the application and development of sensor network technology through the above discussion. 


\section{References}

[1] Sangwan A, Singh R P. Survey on Coverage Problems in Wireless Sensor Networks[J]. Wireless Personal Communications, 2015, 80(4):1475-1500.

[2] Bhatti N A, Alizai M H, Syed A A, et al. Energy Harvesting and Wireless Transfer in Sensor Network Applications: Concepts and Experiences[J]. Acm Transactions on Sensor Networks, 2016, 12(3):24.

[3] Verma V K, Singh S, Pathak N P. Towards comparative evaluation of trust and reputation models over static, dynamic and oscillating wireless sensor networks[J]. Wireless Networks, 2015:1-9.

[4] Sharma S, Sethi D, Bhattacharya P. Artificial Neural Network based Cluster Head Selection in Wireless Sensor Network[J]. Computer Physics Communications, 2015, 174.

[5] Lin J, Jung H, Chang Y J, et al. On cooperative transmission range extension in multi-hop wireless ad-hoc and sensor networks: A review[J]. Ad Hoc Networks, 2015, 29(C):117-134.

[6] Abba S, Lee J A. An Autonomous Self-Aware and Adaptive Fault Tolerant Routing Technique for Wireless Sensor Networks[J]. Sensors, 2015, 15(8):20316-20354. 